\title{
МОЛОДЕЖЬ НОВОГО РАБОЧЕГО КЛАССА КАК ОБЪЕКТ ГОСУДАРСТВЕННОЙ СОЦИАЛЬНОЙ ПОЛИТИКИ И ИНВЕСТИРОВАНИЯ
}

В статье рассматривается необходимость социальных инвестиций в молодежь нового рабочего класса как социальную группу, составляющую основной социальный резерв развития отечественной экономики. Рабочая молодежь рассматривается как гетерогенная группа, в которой выделяются три социальных типа, имеющих специфические запросы относительно приоритетных направлений социального инвестирования. Эмпирическое исследование проведено в 2018 г. с использованием количественных методов. Молодежь рассматривается на пересечении трех стратификационных признаков: социального класса, гендера и возраста. Концептуальным основанием исследования являлась теория баланса/конфликта рабочего и свободного времени. Проведенный факторный анализ позволил выделить две группы факторов, влияющих на восприятие баланса работы и личной жизни среди молодежи нового рабочего класса: факторы удовлетворенности работой и факторы достаточности/дефицита свободного времени. Гипотеза исследования состояла в том, что указанные факторы отражают состояние баланса/ конфликта между работой и личной жизнью респондента и могут выступать в качестве типообразующих признаков дифференцирования рабочей молодежи на три самостоятельных кластера. На основе полученных факторов был осуществлен кластерный анализ и выделены три социальных типа с учетом предварительно разработанной априорной

Владислав Юрьевич Бочаров- к.социол.н., доцент, кафедра социологии и культурологии, Самарский национальный исследовательский университет им. ак. С.П. Королева, Самара; ассоциированный научный сотрудник, Социологический институт РАН- филиал ФНИСЦ РАН, Санкт-Петербург, Россия. Электронная почта: vlad.bocharov@gmail.com

Татьяна Владимировна Гаврилюк-к.социол.н., доцент, старший научный сотрудник, Центр перспективных исследований и инновационных разработок, Тюменский индустриальный университет, Тюмень, Россия. Электронная почта: tv_gavrilyuk@mail.ru 
типологии моделей экономического и трудового поведения рабочей молодежи: «зарабатывающие», «выживающие», «адаптированные». Каждый из этих типов рабочей молодежи обладает особыми трудовыми стратегиями и ценностными приоритетами. Полученная типология позволила обозначить целевые направления социального инвестирования в человеческий капитал для каждого из социальных типов молодежи нового рабочего класса. На уровне программ муниципальных образований направления молодежной социальной политики могут конкретизироваться с учетом территориальной, отраслевой, гендерной и возрастной специфики рабочей молодежи, проживающей на территории данного муниципалитета. В первую очередь, необходимы программы поддержки и социального инвестирования молодых женщин нового рабочего класса, положение которых на рынке труда наиболее уязвимо, а материальное благосостояние, как правило, ниже, чем у мужчин.

Ключевые слова: молодежь, новый рабочий класс, рабочая молодежь, социальное инвестирование, баланс рабочего и свободного времени

DOI: 10.17323/727-0634-2021-19-1-69-84

C конца XX в. глобальные процессы трансформации отношений занятости и прекаризации труда ведут к ухудшению положения наемного персонала: внедрение нестандартных графиков работы, снижение оплаты труда, уменьшение количества социальных пособий и гарантий занятости, сокращение возможностей для карьерного роста и трудовой мобильности, переход к краткосрочным трудовым контрактам, ослабление профсоюзного движения (Kalleberg 2000). В российском контексте эти процессы также обусловлены потребностью в модернизации производства и дефицитом кадров для рабочих профессий, возникшим ввиду низкой заработной платы и невнимания к нуждам наемного персонала со стороны государства и работодателей (Тукумцев, Бочаров 2018). Трансформировался и сам рабочий класс, определение которого в рамках индустриального капитализма больше невозможно. Основываясь на идее Макса Вебера об обмене ресурсов на капиталистическом рынке труда, Джон Голдторп предложил экономически ориентированную классовую модель (Goldthorpe 1966). Его многомерная классовая схема учитывает дифференциацию профессий, характер труда, уровень образования и квалификации, отношения найма и формы занятости. В результате к рабочему классу, помимо непосредственно рабочих, занятых физическим трудом (квалифицированных и неквалифицированных), относятся и работники рутинного нефизического труда низкого уровня (Erikson, Goldthorpe 1992).

На пересечении академической традиции и социально-политического активизма возникло междисциплинарное поле исследований (new working class studies) как дискуссионная площадка, нацеленная на решение практических социальных проблем (Linkon, Russo 2016). Авторы этого направления 
рассматривают последствия неолиберализма для рабочего класса (Zweig 2000), негативные медиарепрезентации данной социальной группы как форму контроля и закрепления существующей структуры социального неравенства (Jones 2012), социальный и культурный капиталы как основополагающие факторы классовой дифференциации (Savage 2000). Рабочие как социальная группа, а не как класс, становятся объектом эмпирических исследований российских авторов, однако до последнего времени их внимание было сосредоточено на работниках промышленного производства (Караханова и др. 2014; Татарова, Бессокирная 2017). Тем не менее появляются исследования, в которых рассматриваются и рабочие сферы услуг, причем нередко в связи с прекарным характером их труда (Тартаковская, Ваньке 2019).

Анализ современного исследовательского поля позволяет определить критерии отделения нового рабочего класса (НРК) от других классов и стратификационных групп: отношения собственности, участие в управлении предприятием, характер и содержание труда. НРК не является гомогенным образованием, его внутренняя дифференциация связана с влиянием таких факторов, как форма найма, сфера занятости, уровень доходов, степень рутинизации труда, стиль жизни и культурный капитал (Гаврилюк 2019: 111). При этом традиционный промышленный рабочий класс представляет собой лишь одну из подгрупп НРК, наряду с другими профессиональными группами. Так, отнесение к НРК работников сферы услуг, занятых рутинизированным трудом, уже стало конвенциональным (Roberts 2012; Shalev 2008: 433). Как основной элемент социальной структуры НРК не является пролетариатом прошлых столетий и не тождественен глобальному прекариату. Это новый большой социальный класс, формирующийся в ходе дифференциации собственников и наемных работников реального сектора экономики современной России. Таким образом, сегодня речь ведется о существовании НРК, к которому следует относить работников, занятых как в сферах промышленного производства, так и услуг. Их труд рутинизирован, разделен на стандартизированные сегменты, поддается алгоритмизации и количественному нормированию результатов; они не участвуют в управлении и не имеют прав собственности в организации, в которой трудятся (Гаврилюк 2019).

Исследования свидетельствуют, что в условиях постиндустриального капитализма серьезной проблемой для наемных работников, занятых на позициях НРК, становится дефицит свободного времени и конфликт между работой и личной жизнью (Chung, van der Lippe 2018). Помимо выявления специфических запросов на реализацию тех или иных направлений социальной политики, теоретические основания концепции баланса работы и личной жизни могут быть применимы для разработки и реализации подхода к социальному инвестированию в молодежь нового рабочего класса (МНРК) со стороны государства и корпораций. НРК является главным трудовым ресурсом новой экономики, переходящей 
в постиндустриальную стадию, поэтому социальное инвестирование в рабочий класс нового типа (включая работников сферы услуг) является актуальным направлением социальной политики. Кроме того, в России принятые на федеральном уровне «Основы государственной молодежной политики до 2025 года» (Правительство РФ 2014) слабо отвечают потребностям рабочей молодежи (Чирикова 2010; Гаврилюк 2019). Проведенный в статье анализ позволяет раскрыть детали восприятия баланса работы и личной жизни среди молодежи нового рабочего класса для целей социальной политики.

\section{Подходы к социальному инвестированию в человеческий капитал}

Потенциальное место России в глобализирующемся мире определяется как с проводимыми на макроуровне экономическими и социальными реформами, так и с качеством ее человеческого потенциала. Огромную роль здесь призвана играть реализуемая государством социальная политика, рассматриваемая не как привычная по советскому прошлому система социального обеспечения, а как инвестиционный механизм, формирующий главную составляющую богатства страны в современном мире - человеческий капитал (Горшков и др. 2008). Воплощение в реальность такой модели социальной политики предполагает «увеличение доли лиц, реализующих профессионально активный тип экономического поведения» (Соколова 2004: 63). В рамках подхода, основанного на «парадигме труда», сменившей «парадигму капитала» (Люблинский 2010: 130), приоритетом социальной политики должно стать здоровье и образование человека (Григорьева 2003). Переход к «парадигме труда» может быть успешно осуществлен с помощью разработки комплекса социально-экономических мероприятий, ориентированных не на всю совокупность населения, а выделяющих социально-демографические группы и формирующих «адресные пакеты» для каждой из них. У различных групп россиян существуют разные запросы к государственной социальной политике, согласующиеся с их потребностями (Мареева 2010), поэтому важно учитывать гетерогенность существующих социально-демографических групп с точки зрения классовой структуры, возраста, гендерной принадлежности и места жительства.

Характерной особенностью социального инвестирования является привлечение и выделение ресурсов для решения проблем, нацеленных на развитие человеческого капитала (Данилова 2010). Такое инвестирование возможно и в рамках корпоративной политики, одной из миссий которой является ведение социально ответственного бизнеса, способного дать конкурентные преимущества и повысить социальную репутацию, а наемным работникам обеспечить увеличение заработной платы и улучшение социального пакета (Абрамович, Стрижов 2017). В отличие от социальной 
защиты населения, направленной на поддержание определенного уровня жизни, социальное инвестирование ориентировано именно на повышение уровня и качества жизни (Водяненко 2019: 51). Сегодня нет устоявшихся определений социального инвестирования, но существуют широкие трактовки, которые справедливо допускают возможность применения данной концепции к анализу трудовой деятельности и рассматривают эффективно функционирующий рынок труда в качестве связующего звена между развитием человеческого потенциала, системой управления трудовыми ресурсами и экономическим ростом (Сагидов 2013: 88; cp., Garritzmann et al. 2018; Аникин и др. 2019: 351).

Важной проблемой современных исследований является поиск оптимального баланса рабочего и свободного времени, который ведется, как правило, в гендерном измерении (Zannella et al. 2019). Актуальными направлениями изучения данных проблем являются анализ конфликта между работой и личной жизнью, work-life conflict (Chung, van der Lippe 2018); анализ конфликта между работой и семьей, work-family conflict (Annink et al. 2016; Chung 2020); анализ влияния режима работы на социальное самочувствие работников, subjective well-being (Begall, Mills 2011). Эти подходы взаимосвязаны между собой, однако work-life conflict является наиболее широким и используется в нашем исследовании в классовом измерении. При этом наше исследование подтверждает известный тезис, что женщины из рабочего класса, имея меньше финансовых ресурсов, находятся в наиболее тяжелом положении, неся двойное бремя оплачиваемой и неоплачиваемой домашней работы (Гаврилюк 2020:278-279).

\section{Методология и методика исследования}

Сбор данных для этого исследования был проведен в 2018 г. (Гаврилюк 2019). Объектом массового анкетного опроса являлась молодежь 15-29 лет, проживающая на территории Уральского Федерального округа (1534 респондента). Использована целевая многоступенчатая выборка (ошибка выборки не превышает 5\%) по четырем объективным критериям: (1) возраст: около 500 человек в каждой из возрастных групп, соответствующих периодизации когорт в официальной статистике РФ-15-19 (33\%), 20-24 (33,4\%) и 25-29 (33,6\%) лет; (2) пол: мужской (50,3\%) и женский $(49,7 \%)$; (3) место жительства: город $(76,2 \%)$ и сельская местность $(23,8 \%)$ в соответствии с распределением населения в УрФО; (4) сфера занятости: промышленность и техническое обслуживание (45,2\%), клиентский сервис (54,8\%).

Молодежь рассмотрена на пересечении трех стратификационных признаков: социального класса (представители НРК), гендера и возраста. Концептуальным основанием исследования являлась концепция баланса/конфликта рабочего и свободного времени. Главной задачей исследования стало выделение типов рабочей молодежи на основе факторного и кластерного 
анализа данных, а также определение перспектив рассмотрения выделенных социальных типов в качестве потенциальных объектов социального инвестирования в рамках реализации направлений региональной молодежной социальной политики.

\section{Рабочее время и уровень удовлетворенности графиком работы}

По данным опроса, 40 \% МНРК имеют стандартный режим работы, согласно действующему российскому трудовому законодательству, 40-часовую пятидневную рабочую неделю. Почти каждый третий $(32,1$ \%) опрошенный указал, что обычный рабочий день длится 9-10 или больше 10 часов, т.е. они перерабатывают установленный в законе норматив. С другой стороны, 12,9\% опрошенных работают по сокращенному режиму (менее 8 часов день), а еще 11 \% указали, что их рабочий день предполагает гибкий график и разную величину рабочих часов в день. В целом по массиву опрошенных 63,8\% МНРК удовлетворены своим графиком работы. Среди тех, кого график не устраивает, причинами неудовлетворенности назывались: «недостаточные для восстановления сил промежутки времени в течение рабочего дня» $(10,6 \%)$, «мы часто задерживаемся на работе, переработки не оплачиваются» $(10,0 \%)$ и «слишком много рабочих часов в неделю, не успеваю отдохнуть» $(9,7$ \%). Женщины удовлетворены графиком работы в меньшей степени, чем мужчины.

Респонденты обеих гендерных групп, занятые более 8 часов в день, чаще склоняются к мнению, что работа оказывает негативное влияние на их здоровье. Если в среднем по массиву такого мнения придерживаются $32,5 \%$ мужчин и 48,3\% женщин, то среди занятых более 8 часов о негативном влиянии работы на их здоровье указывают $37,3 \%$ мужчин и 57,1 \% женщин (табл. 1) ${ }^{1}$.

Только 40,2\% опрошенных смогли согласиться, что имеют достаточно времени на отдых и восстановление сил после работы. От 40 до 65\% молодежи (по разным показателям) испытывают дефицит свободного времени на удовлетворение коммуникативных и досуговых потребностей. Дефицит свободного времени ощущается респондентами для занятий спортом, развлечений, хобби, а также для самообразования и саморазвития. Среди женщин дефицит свободного времени ощущается острее по всем выделенным в исследовании показателям. Лишь каждая третья женщина (32,3\%) имеет достаточно времени на отдых и восстановление сил после работы. Особенно остро проблема дефицита свободного времени ощущается женщинами, чей рабочий день длится более 8 часов (табл. 1).

\footnotetext{
${ }^{1} \mathrm{C}$ подробными данными можно ознакомиться в электронном приложении: https://jsps. hse.ru/article/view/12240.
} 


\section{Факторы удовлетворенности работой}

Данные исследования свидетельствуют о наличии взаимосвязи между удовлетворенностью графиком и содержанием выполняемой работы, трудовыми отношениями и другими параметрами удовлетворенности работой (табл. 2). Было выделено три фактора, каждый из которых включает два показателя. Им присвоены условные имена: (1) «работа по душе»: удовлетворенность содержанием работы и предприятием; (2) «комфорт и общение»: удовлетворенность трудовым коллективом и социальным пакетом; (3) «материальное вознаграждение»: удовлетворенность заработной платой и системой премирования.

\section{Факторы достаточности (дефицита) свободного времени}

Факторы удовлетворенности работой представляют собой лишь одну сторону баланса «работа- личная жизнь». В качестве второй стороны рассматриваются показатели достаточности/дефицита свободного времени через оценки респондентов, которые напрямую связаны с физическим и психическим здоровьем, удовлетворенностью жизнью и уровнем социального самочувствия. Исследователи признают, что показатели достаточности свободного времени применимы для прогнозирования в качестве независимых переменных (Roberts 2019:249). При этом «свободное время» трактуется как свободное от оплачиваемого и неоплачиваемого труда, а также от видов деятельности, направленных на удовлетворение физиологических потребностей индивида (Караханова и др. 2014: 101).

Среди всех параметров достаточности/дефицита свободного времени (табл. 2) было выделено три фактора, каждый из которых оказался нагружен только одной переменной: (1) «время на хобби и увлечения»; (2) «время на общение с семьей»; (3) «время на самообразование и саморазвитие». После процедуры стандартизации эти переменные, наряду с факторами удовлетворенности работой, использовались в ходе проведения последующего кластерного анализа.

\section{Выделение типов рабочей молодежи методом кластерного анализа}

В этом исследовании осуществляется кластерный анализ методом К-среднего (K-Means). После проверки всех выбранных стандартизованных переменных и факторов наиболее устойчивой моделью оказалось трехкластерное решение. Обоснованность трехкластерной модели подтверждают показатели $F$-статистики и величина статистической значимости $(\mathrm{Sig})$ таблицы одномерного однофакторного дисперсионного анализа ( $A N O V A)$.

По результатам кластерного анализа были выделены три социальных типа рабочей молодежи: «зарабатывающие» (35,6\%), «выживающие» $(40,2 \%)$ и «адаптированные» $(24,2$ \%). Выделенные социальные типы согласуются 
с описанными на предыдущем этапе тремя априорными моделями экономического и трудового поведения рабочей молодежи (Гаврилюк 2019): «зарабатывающие» соответствуют модели «активное действие», «выживающие»- модели «терпеливое молчание», а «адаптированные»- модели «адаптивное приспособление».

\section{«Зарабатывающие»}

Для рабочей молодежи этого типа характерна успешная реализация профессиональных навыков. Условия работы с благоприятным графиком, но уровень комфорта и общения на рабочем месте низкий, есть определенный дефицит времени на саморазвитие и увлечения. Таких работников можно назвать индивидуалистами, ориентированными на материальный успех, не обращающих внимания на коллег и на дефицит времени. Они ощущают конфликт между работой и личной жизнью, но из-за сознательной ориентации на материальные блага и карьеру переживают его не очень остро. Респонденты этого кластера чаще всего имеют стандартный 8-часовой рабочий день (44,9\%), как мужчины (50,8\%), так и женщины (49,2\%). Основная трудовая стратегия- зарабатывание денег. Приоритетной является работа в рамках стандартного трудового графика. Они планируют много времени или всю жизнь посвятить карьере в профессии, которой сейчас заняты.

\section{«Выживающие»}

В рамках этого социального типа представлена рабочая молодежь, наиболее остро ощущающая конфликт между работой и личной жизнью из-за неблагоприятных условий работы и дефицита свободного времени. Здесь превалируют женщины- 56,3\%, в то время как мужчин-43,7\%. Представители этого кластера часто работают более 8 часов в день (42,9\%), среди них больше всего доля тех, кто считает, что работа негативно влияет на их здоровье (49,4\%). Основная трудовая стратегия- выживание в неблагоприятных условиях рабочей среды и дефицита свободного времени. Работа не является приоритетом- лишь вынужденным инструментом для выживания. Им часто приходится работать в режиме сверхнормативной занятости (больше 8 часов в день), имея при этом нестандартный (сменный) график работы.

\section{«Адаптированные»}

Здесь представлена рабочая молодежь, которая ориентирована преимущественно на факторы свободного времени и в меньшей степени на факторы рабочей среды (кроме фактора «комфорт и общение»). Среди этого кластера мужчин $62 \%$, в то время как женщин- только $38 \%$. Они не ощущают острого конфликта между работой и личной жизнью, способны адаптироваться к различным видам трудовой деятельности. В ущерб заработку они готовы проводить рабочее время в комфортной обстановке 
за общением с коллегами, стараясь сохранять приемлемый баланс между работой и свободным временем. Они способны адаптироваться к различным видам трудовой деятельности, т.к. в их системе ценностей работа не обладает первостепенным значением. По сравнению с другими типами, респонденты этого кластера чаще работают менее 8 часов в день $(16,4 \%)$. Основная трудовая стратегия- прагматическая, минимизирующая трудовые затраты, мимикрирующая и встраиваемая в социальные институты, адаптируемая к их требованиям, с минимально возможными потерями для собственного свободного времени. Ни работа, ни семья не являются для носителей этого типа важнейшими ценностями. Они делают акцент на личном развитии (в их собственном понимании) и беззаботном времяпрепровождении. Чаще всего ориентированы на нестандартный режим работы (менее 8 часов в день), отдавая предпочтение свободному графику.

\section{Приоритетные направления социального инвестирования в развитие потенциала МНРК}

Данные опроса свидетельствуют, что основными темами, которые волнуют сегодня рабочую молодежь и которые они хотели бы видеть в качестве приоритетных направлений региональной социальной политики, являются: (1) помощь в решении жилищных проблем молодой семьи; (2) помощь в решении проблем трудоустройства, т. е. адаптации на рынке труда; (3) пропаганда здорового образа жизни, включая профилактику наркомании; (4) чуть в меньшей степени, но также достаточно сильно выражен запрос на доступность качественного профессионального образования и поддержку карьерного роста. В зависимости от социального типа наблюдаются различия в запросах на социальную поддержку и инвестирование (табл. 3). Таким образом, мы можем предложить основные направления для целевого социального инвестирования, которое может осуществляться как на уровне государственного управления регионами, так и быть отражено в корпоративных программах по социальному развитию рабочей молодежи.

На уровне программ муниципальных образований молодежная политика может конкретизироваться с учетом территориальной, отраслевой, гендерной и возрастной специфики рабочей молодежи, проживающей на территории муниципалитета. Например, в гендерном аспекте, в первую очередь, необходимы программы социальной поддержки молодых женщин НРК, положение которых на рынке труда наиболее уязвимо, а материальное благосостояние, как правило, ниже, чем у мужчин (табл. 4). Отмеченные в таблице 4 «плюсы и минусы» отражают существующий запрос самой рабочей молодежи. Это не значит, что он не может измениться, но важно понимать, что карьерный рост и повышение уровня образования интересуют лишь 1/3 МНРК. Для остальных приоритетом является поиск путей 
выживания в ситуации чрезмерной трудовой нагрузки, в условиях неудобного графика работы и низких заработков.

В такой ситуации становится очевидно, почему существующие на сегодняшний день молодежные программы имеют ограниченную эффективность, особенно для рассматриваемой нами социальной группы: они игнорируют классовую и гендерную специфику, а также более тонкие различия, обусловленные культурными факторами социальной среды (образование, воспитание, субкультурная принадлежность) и жизненными стратегиями самой молодежи. Неудивительно, что участники исследования обнаружили низкую заинтересованность в государственных программах поддержки молодежи, считая, что если такие программы и существуют (многие о них ничего не знают), то они не предназначены для «простых людей».

\section{Заключение}

Исследование МНРК показало, что при увеличении нагрузки рабочего времени сокращается удовлетворенность состоянием баланса между работой и личной жизнью. Особенно негативно конфликт между работой и личной жизнью переживают женщины, которые в силу сохранившихся гендерных стереотипов, а также слабости государственных институтов защиты и поддержки семьи продолжают нести основное бремя нагрузки неоплачиваемой домашней работы и ухода за детьми. Неслучайно среди женщин больше, чем среди мужчин, распространено мнение о негативном влиянии работы на их здоровье, и в зависимости от увеличения длительности рабочего дня такое мнение у женщин только усиливается. Именно женщины ощущают дефицит свободного времени гораздо сильнее, чем мужчины. При этом модельной группой рабочей молодежи оказываются те, кто работает наиболее интенсивно при максимально длительном рабочем времени, но не имеет возможности удовлетворить в полной мере свои потребности и оказывается в условиях стратегии выживания.

Факторный анализ позволил выделить две группы факторов, влияющих на восприятие баланса работы и личной жизни рабочей молодежью: удовлетворенности работой и достаточности/дефицита свободного времени. Выявлено существенное влияние фактора режима рабочего времени на состояние баланса работы и личной жизни, причем молодые женщины более остро ощущают указанный конфликт. По результатам кластерного анализа выделены три социальных типа рабочей молодежи («зарабатывающие», «выживающие», «адаптированные»), каждый из которых обладает особыми трудовыми стратегиями и ценностными приоритетами. Наличие данных типов необходимо принимать во внимание при разработке программ социальной политики и целевых направлений социального инвестирования, направленных на рабочую молодежь. 
Результаты нашего исследования показывают, что наиболее нуждающимися в мерах социальной поддержки являются молодые женщины (особенно социального типа «выживающие»). Приоритетными субъектами адресного социального инвестирования, напротив, являются представители обеих гендерных групп МНРК социальных типов «зарабатывающие» и «адаптированные»: инструментами, способствующими эффективному росту капитала этих социальных групп, могут служить программы повышения квалификации и уровня профессионального образования для «адаптированных» и программы карьерного роста и возможности для трудовой мобильности для «зарабатывающих». В этой связи одной из действенных мер на государственном уровне было бы принятие поправок и дополнений в существующие основы молодежной политики, которые сегодня не содержат самого понятия «молодой рабочий». Выделение категории молодых рабочих, имеющих в силу своей классовой принадлежности неравные по сравнению со средним классом шансы на доступ к качественному образованию и карьерное продвижение, должно сопровождаться перечнем конкретных направлений их поддержки, реализуемых на уровне субъектов федераций. Поэтому целесообразно разработать и принять для субъектов федерации рамочную концепцию молодежной социальной политики с условным названием «Рабочая молодежь». В этой концепции должно быть не только дано четкое определение рабочей молодежи, но и заданы приоритетные направления социальной поддержки и инвестирования, с учетом гендерного и территориального аспекта, специфики сферы занятости (промышленность и сфера услуг), а также социальной типологии МНРК.

\section{Выражения благодарности}

Статья подготовлена при поддержке гранта РНФ № 17-78-20062 «Жизненные стратегии молодежи нового рабочего класса в современной России».

Редакция благодарит программу Университетское партнерство за поддержку и возможность опубликовать данную статью.

\section{Список источников}

Абрамович С. Ю., Стрижов С. А. (2017) Социально ответственное инвестирование в повестке дня устойчивого развития. Инновациии и инвестиц̧ии, (8): 13-17.

Аникин В.А., Лежнина Ю. П., Мареева С. В., Слободенюк Е. Д. (2019) Запросы россиян на содействие государства: социальное инвестирование или социальная поддержка? Мониторинг общественного мнения, (3): 345-366.

Водяненко О.И. (2019) Теоретико-методологические аспекты исследования института социального инвестирования. Теоретическая экономика, 2 (50): 48-53. 
Гаврилюк Т. В. (ред.) (2019) Молодежь нового рабочего класса современной России. М.: Флинта.

Гаврилюк Т.В. (ред.) (2020) Жизненные стратегии молодежи нового рабочего класса. М.: Флинта.

Горшков М.К., Тихонова Н.Е., Мареева С. В. (2008) Роль социальной политики в повышении конкурентоспособности России на международной арене. М.К. Горшков (ред.) Россия в глобальных проиессах: поиски перспективы. М.: Институт социологии РАН: 8-25.

Григорьева И. А. (2003) Социальная политика: основные понятия. Журнал исследований социальной политики, 1 (1):29-44.

Данилова О.В. (2010) Социальное инвестирование как экономическая закономерность современной эпохи. Национальные интересы: приоритеты и безопасность, 23 (80): 14-19.

Караханова Т. М., Бессокирная Г.П., Большакова О. А. (2014) Труд и досуг рабочих (программа, инструментарий и некоторые предварительные результаты повторного исследования). М.: Институт социологии РАН.

Люблинский В.В. (2010) Социальная политика в странах Запада: новые вызовы и характер трансформации. Вестник Института сочиологии, (1): 121-132.

Мареева С.В. (2010) Запрос россиян на определенный тип развития страны и социальноэкономическую политику. Вестник Института сочиологии, (1): 124-153.

Правительство РФ (2014) Основы государственной молодежной политики Российской Федеращии на период до 2025 года № 2403-р от 29.11.2014.

Сагидов А.К. (2013) Социальное инвестирование как инструмент управления трудовыми ресурсами. Вестник Махачкалинского филиала МАДИ, (13): 87-89.

Соколова Г.Н. (2004) Социальная политика государства в сфере труда и трудовых отношений. Социологические исследования, (4): 60-63.

Тартаковская И.Н., Ваньке А.В. (2019) Трудовые траектории прекарных работников и формирование прекарного габитуса. Сочиологический журнал, 25 (2):99-115.

Татарова Г.Г., Бессокирная Г.П. (2017) Удовлетворенность работой как конструкт в эмпирических исследованиях. Социологический журнал, 23 (1): 8-26.

Тукумцев Б.Г., Бочаров В.Ю. (2018) Низкий уровень жизни как социальное препятствие на пути модернизации промышленного производства. Петербургская социология сегодня, (10): 7-37.

Чирикова А.Е. (2010) Возможна ли сегодня модернизация социальной политики в России? Вестник Института социологии, (1): 99-119.

Annink A., den Dulk L., Steijn B. (2016) Work-Family Conflict among Employees and the Self-Employed Across Europe. Social Indicators Research, (126):571-593.

Begall K., Mills M. (2011) The Impact of Subjective Work Control, Job Strain and Work-Family Conflict on Fertility Intentions: a European Comparison. European Journal of Population, (27): 433-456. 
Chung H. (2018) Dualization and the Access to Occupational Family-friendly Workingtime Arrangements Across Europe. Social Policy and Administration, 52 (2):491-507.

Chung H., van der Lippe T. (2020) Flexible Working, Work-life Balance, and Gender Equality: Introduction. Social Indicators Research, (151):365-381.

Erikson R., Goldthorpe J.H. (1992) The Constant Flux: A Study of Class Mobility in Industrial Societies. Oxford: Clarendon Press.

Garritzmann J.L., Busemeyer M. R., Neimanns E. (2018) Public Demand for Social Investment: New Supporting Coalitions for Welfare State Reform in Western Europe? Journal of European Public Policy, 25 (6): 844-861.

Goldthorpe J.H. (1966) Social Stratification in Industrial Society. Class, Status, and Power. Social Stratification in Comparative Perspective. London: Routledge.

Jones O. (2012) Chavs: The Demonization of the Working Class. London: Verso.

Kalleberg A.L. (2000) Nonstandard Employment Relations: Part-time, Temporary, and Contract Work. Annual Review of Sociology, (26):341-365.

Linkon S.L., Russo J. (2016) Twenty Years of Working-class Studies: Tensions, Values, and Core Questions. Journal of Working-Class Studies, 1 (1): 4-13.

Roberts K. (2019) A Future for UK Leisure Studies: Back to Work. International Journal of the Sociology of Leisure, 2 (3): 239-253.

Roberts S. (2012) Boys will Be Boys... Won’t they? Change and Continuities in Contemporary Young Working-class Masculinities. Sociology, 47 (4): 671-686.

Savage M. (2000) Class Analysis and Social Transformation. Buckingham: Open University Press.

Shalev M. (2008) Class Divisions among Women. Politics \& Society, 36 (3): 421-444.

Zannella M., Hammer B., Prskawetz A., Sambt J. (2019) A Quantitative Assessment of the Rush Hour of Life in Austria, Italy and Slovenia. European Journal of Population, (35): 751-776.

Zweig M. (2000) The Working-class Majority. Ithaca: Cornell University Press. 
Vladislav Bocharov, Tatiana Gavrilyuk

\title{
THE NEW WORKING-CLASS YOUTH AS THE OBJECT OF STATE SOCIAL POLICY AND INVESTMENT
}

\begin{abstract}
This article focuses on new working-class youth investment as a social group that makes up the main social reserve for domestic economic development. Working-class youth itself has been regarded as a heterogeneous group, in which three social types can be distinguished that have specific requests regarding the priority areas of social investment. Our empirical study was conducted in 2018 using quantitative methods. We examine new working-class youth at the intersection of class, gender and age. The conceptual basis of the study was the theory of working and free time balance. A factor analysis was carried out to distinguish two groups of factors affecting the perception of work and personal-life balance among young people of the new working class: job satisfaction and free time. Based on the obtained factors, a cluster analysis was carried out and three labour behaviour models were identified for working-class youth: 'earning', 'surviving' and 'adapted' types. This typology allowed us to identify the target areas of social investment in human capital for each of the social types of the new working-class youth. At the level of municipal programs, the directions of youth social policy can be specified taking into account the territorial, sectoral, gender and age specifics of working-class youth living in the territory of this municipality. First of all, support and social investment programs are needed for young women of the new working class, whose position on the labour market is the most vulnerable, and whose material well-being, as a rule, is lower than that of men.
\end{abstract}

Key words: youth, new working class, working-class youth, social investment, work and personal-life time balance

DOI: 10.17323/727-0634-2021-19-1-69-84

\section{References}

Abramovich S. Yu., Strizhov S. A. (2017) Sotsial'no otvetstvennoe investirovanie v povestke dnya ustoychivogo razvitiya [Socially Responsible Investment as a Tool to Achieve Sustainable Development Goals]. Innovatsii i investitsii [Innovation and Investment], (8): 13-17.

Anikin V.A., Lezhnina Yu.P., Mareeva S. V., Slobodenyuk E.D. (2019) Zaprosy rossiyan na sodeystvie gosudarstva: sotsial'noe investirovanie ili sotsial'naya podderzhka? [Russian Public Demand

Vladislav Bocharov- Cand. Sci. (Soc.), Associate Professor, the Chairman of Sociology and Cultural Studies at Sociological department, Samara National Research University; associate research fellow, The Sociological Institute of the Russian Academy of Sciences, St. Petersburg, Russian Federation. Email: vlad.bocharov@gmail.com

Tatiana Gavrilyuk - Cand. Sci. (Soc.), Associate Professor, senior researcher of the Center for Advanced Research and Innovation, Industrial University of Tyumen, Tyumen, Russian Federation. Email: tv_gavrilyuk@mail.ru 
for State Assistance: Social Investment or Social Support?]. Monitoring obshchestvennogo mneniya [Monitoring of Public Opinion], (3):345-366.

Annink A., den Dulk L., Steijn B. (2016) Work-Family Conflict among Employees and the SelfEmployed Across Europe. Social Indicators Research, (126):571-593.

Begall K., Mills M. (2011) The Impact of Subjective Work Control, Job Strain and Work-Family Conflict on Fertility Intentions: a European Comparison. European Journal of Population, (27): 433-456.

Chirikova A.E. (2010) Vozmozhna li segodnya modernizatsiya sotsial'noy politiki v Rossii? [Is Modernization of Social Policy in Russia Possible Today?]. Vestnik instituta sotsiologii [Bulletin of the Institute of Sociology], (1): 99-119.

Chung H. (2018) Dualization and the Access to Occupational Family-friendly Working-time Arrangements Across Europe. Social Policy and Administration, 52 (2): 491-507.

Chung H., van der Lippe T. (2020) Flexible Working, Work-life Balance, and Gender Equality: Introduction. Social Indicators Research, (151):365-381.

Danilova O. V. (2010) Sotsial'noe investirovanie kak ekonomicheskaya zakonomernost' sovremennoy epokhi [Social Investment as an Economic Regularity of the Modern Era]. Natsional'nye interesy: prioritety i bezopasnost' [National Interests: Priorities and Security], 23 (80): 14-19.

Erikson R., Goldthorpe J.H. (1992) The Constant Flux: A Study of Class Mobility in Industrial Societies. Oxford: Clarendon Press.

Garritzmann J.L., Busemeyer M. R., Neimanns E. (2018) Public Demand for Social Investment: New Supporting Coalitions for Welfare State Reform in Western Europe? Journal of European Public Policy, 25 (6): 844-861.

Gavrilyuk T.V. (ed.) (2019) Molodezh' novogo rabochego klassa sovremennoy Rossii [New Working-class Youth in Modern Russia]. Moscow: Flinta.

Gavrilyuk T.V. (ed.) (2020) Zhiznennye strategii molodezhi novogo rabochego klassa [Life Strategies of New Working-class Youth]. Moscow: Flinta.

Goldthorpe J.H. (1966) Social Stratification in Industrial Society. Class, Status, and Power. Social Stratification in Comparative Perspective. London: Routledge.

Gorshkov M. K., Tikhonova N.E., Mareeva S. V. (2008) Rol' sotsial'noy politiki v povyshenii konkurentosposobnosti Rossii na mezhdunarodnoy arene [The Role of Social Policy in Enhancing the Competitiveness of Russia in the International Arena]. In: M. K. Gorshkov (ed.) Rossiya v global'nykh protsessakh: poiski perspektivy [Russia in Global Processes: Search for Prospects]. Moscow: Institut sotsiologii RAN: 8-25.

Grigor'eva I.A. (2003) Sotsial'naya politika: osnovnye ponyatiya [Social Policy: Basic Concepts]. Zhurnal Issledovanii Sotsial'noi Politiki [The Journal of Social Policy Studies], 1 (1):29-44.

Jones O. (2012) Chavs: The Demonization of the Working Class. London: Verso.

Kalleberg A. L. (2000) Nonstandard Employment Relations: Part-time, Temporary, and Contract Work. Annual Review of Sociology, (26):341-365.

Karakhanova T.M., Bessokirnaya G. P., Bol'shakova O.A. (2014) Trud i dosug rabochikh (programma, instrumentariy i nekotorye predvaritel'nye rezul'taty povtornogo issledovaniya) [Work and Leisure of Workers (Program, Tools and Some Preliminary Results of a Repeated Study)]. Moscow: Institut sotsiologii RAN.

Linkon S.L., Russo J. (2016) Twenty Years of Working-class Studies: Tensions, Values, and Core Questions. Journal of Working-Class Studies, 1 (1):4-13. 
Lyublinskiy V.V. (2010) Sotsial'naya politika v stranakh Zapada: novye vyzovy i kharakter transformatsii [Social Policy in Western Countries: New Challenges and the Nature of Transformation]. Vestnik instituta sotsiologii [Bulletin of the Institute of Sociology], (1): 121-132.

Mareeva S.V. (2010) Zapros rossiyan na opredelennyy tip razvitiya strany i sotsial'no-ekonomicheskuyu politiku [The Request of Russians for a Certain Type of Development and Socio-economic Policy]. Vestnik instituta sotsiologii [Bulletin of the Institute of Sociology], (1): 124-153.

Roberts K. (2019) A Future for UK Leisure Studies: Back to Work. International Journal of the Sociology of Leisure, 2 (3): 239-253.

Roberts S. (2012) Boys will Be Boys... Won't They? Change and Continuities in Contemporary Young Working-class Masculinities. Sociology, 47 (4): 671-686.

Government of the RF (2014) Osnovy gosudarstvennoy molodezhnoy politiki Rossiyskoy Federatsii na period do 2025 goda [Fundamentals of the State Youth Policy of the Russian Federation for the Period until 2025] N 2403-p dated 29.11.2014.

Sagidov A.K. (2013) Sotsial'noe investirovanie kak instrument upravleniya trudovymi resursami [Social Investment as a Tool for Managing Labour Resources]. Vestnik makhachkalinskogo filiala MADI [Bulletin of the Makhachkala Branch of MADI], (13): 87-89.

Savage M. (2000) Class Analysis and Social Transformation. Buckingham: Open University Press. Shalev M. (2008) Class Divisions among Women. Politics \& Society, 36 (3): 421-444.

Sokolova G. N. (2004) Sotsial'naya politika gosudarstva v sfere truda i trudovykh otnosheniy [Social Policy of the State in the Field of Labour and Labour Relations]. Sotsiologicheskie issledovaniya [Sociological Studies], (4): 60-63.

Tartakovskaya I. N., Van'ke A.V. (2019) Trudovye traektorii prekarnykh rabotnikov i formirovanie prekarnogo gabitusa [The Mobility Strategies of Precarious Employees and the Formation of a Precarious Habitus]. Sotsiologicheskiy zhurnal [Sociological Journal], 25 (2): 99-115.

Tatarova G. G., Bessokirnaya G. P. (2017) Udovletvorennost' rabotoy kak konstrukt v empiricheskikh issledovaniyakh [Job Satisfaction as a Construct in Empirical Research]. Sotsiologicheskiy zhurnal [Sociological Journal], 23 (1): 826.

Tukumtsev B. G., Bocharov V. Yu. (2018) Nizkiy uroven' zhizni, kak sotsial'noe prepyatstvie na puti modernizatsii promyshlennogo proizvodstva [Low Standards of Living as a Social Obstacle on the Path to Industrial Modernization]. Peterburgskaya sotsiologiya segodnya [St. Petersburg Sociology Today], (10): 7-37.

Vodyanenko O.I. (2019) Teoretiko-metodologicheskie aspekty issledovaniya instituta sotsial'nogo investirovaniya [Theoretical and Methodological Aspects of the Study of the Institution of Social Investment]. Teoreticheskaya ekonomika [Theoretical Economics], 2 (50): 48-53.

Zannella M., Hammer B., Prskawetz A., Sambt J. (2019) A Quantitative Assessment of the Rush Hour of Life in Austria, Italy and Slovenia. European Journal of Population, (35): 751-776.

Zweig M. (2000) The Working-class Majority. Ithaca: Cornell University Press. 